\title{
Traceability of Asiago Mountain Cheese: A Rapid, Low-Cost Analytical Procedure for its Identification Based on Solid-Phase Microextraction
}

\author{
G. Favaro, ${ }^{1}$ F. Magno, ${ }^{1}$ A. Boaretto, ${ }^{1}$ L. Bailoni, ${ }^{2}$ and R. Mantovani ${ }^{2}$ \\ ${ }^{1}$ Department of Chemical Sciences, University of Padova, Via Marzolo 1, 35131 Padova, Italy \\ ${ }^{2}$ Department of Animal Sciences, University of Padova, Agripolis, Viale dell'Università 16, \\ 35020, Legnaro (PD), Italy
}

\section{ABSTRACT}

The traceability of Asiago mountain cheese was established by analyzing samples of herbaceous species, milk, and cheese of mountain origin using the headspace solid-phase microextraction sampling procedure coupled with gas chromatography-mass spectrometry. As preliminary work had highlighted the characteristic presence of sesquiterpenes in Asiago mountain cheese, these species were considered effective markers of mountain origin. Systematic qualitative analysis, carried out using a carboxen/polydimethylsiloxane fiber, revealed several sesquiterpenes in mountain herbage and milk, in particular $\beta$-caryophyllene and $\alpha$-humulene, in Asiago mountain cheese, confirming sesquiterpenes as markers of cheese produced from animals grazing on mountain pastures. Analysis was performed on 19 samples of herbage, 8 of milk, and 8 of cheese, collected in summer from 4 mountain farms on the Asiago plateau. For quantitative analysis of caryophyllene in cheese, polydimethylsiloxane fiber sampling, coupled with the standard addition method to eliminate matrix effect, was preferred. The amount of $\beta$-caryophyllene found ranged from 21 to $65 \mu \mathrm{g} / \mathrm{kg}$.

(Key words: terpenes, sesquiterpenes, solid-phase microextraction, gas chromatography-mass spectrometry)

Abbreviation key: GC-MS = gas chromatographymass spectrometry, PDMS = polydimethylsiloxane, SPME = solid-phase microextraction, TIPB = triisopropyl benzene.

\section{INTRODUCTION}

Food traceability and knowledge of the relationship between production processing and food composition are of growing interest, due to the rising demand for genuineness, high quality, and origin assurance of food

Received March 18, 2005.

Accepted June 21, 2005.

Corresponding author: G. Favaro; e-mail: gabriella.favaro@ unipd.it. products. Several researchers have approached the problem of certain specific properties of various foods that allow their provenance to be correctly identified (Cardinal et al., 2001; Cozzolino et al., 2002; Fernandez et al., 2003; Mauriello et al., 2003; Pillonel et al., 2003a; Plastow et al., 2003), and many papers on the origin of various kinds of cheese have been published (Careri et al., 2003; Pillonel et al., 2003b,c). In particular, some researchers have turned their attention to differentiating cheeses of mountain or lowland origin by examining a particular class of substances, the terpenes (Mariaca et al., 1997; Viallon et al., 1999, 2000; Bugaud et al., 2001a,b). Terpenes are lipophilic aliphatic compounds, of general formula $\left(\mathrm{C}_{5} \mathrm{H}_{8}\right)_{\mathrm{n}}$, present in particular herbaceous species; for example, the Asteraceae typical of highland pastures. Mariaca et al. (1997) identified terpenes as markers of cheese origin, in terms of altitude, by the sequence plant-animal-milk-cheese. Bugaud et al. (2001c) then established a relationship between the flavor and chemical composition of Abondance cheese and its production from animals grazing on mountain pastures.

The purge-and-trap technique, coupled with gas chromatography-mass spectrometry (GC-MS), is a suitable tool for analyzing the aromatic fractions of milk and cheese, including terpenes (Mariaca et al., 1997; Viallon et al., 2000). Solid-phase microextraction (SPME), which utilizes a very economical sampling procedure, has been successfully used in headspace analysis (Jaillais et al., 1999; Lecanu et al., 2002; Pillonel et al., 2002; Lee et al., 2003; Povolo and Contarini, 2003) and in particular in the analysis of cheese (Pinho et al., 2002, 2003, 2004). Contarini and Povolo (2002) noted that extraction yields obtained with the SPME and purgeand-trap techniques differed, according to the molecular weight of the analytes. Based on these reports, the present paper demonstrates that the traceability of Asiago mountain cheese can be ascertained using terpenes and sesquiterpenes as markers and, at the same time, confirms that the SPME technique can be profitably applied to the problem, from both a qualitative and a quantitative point of view. The final aim was to increase the value of mountain farms, ascertaining mountain 


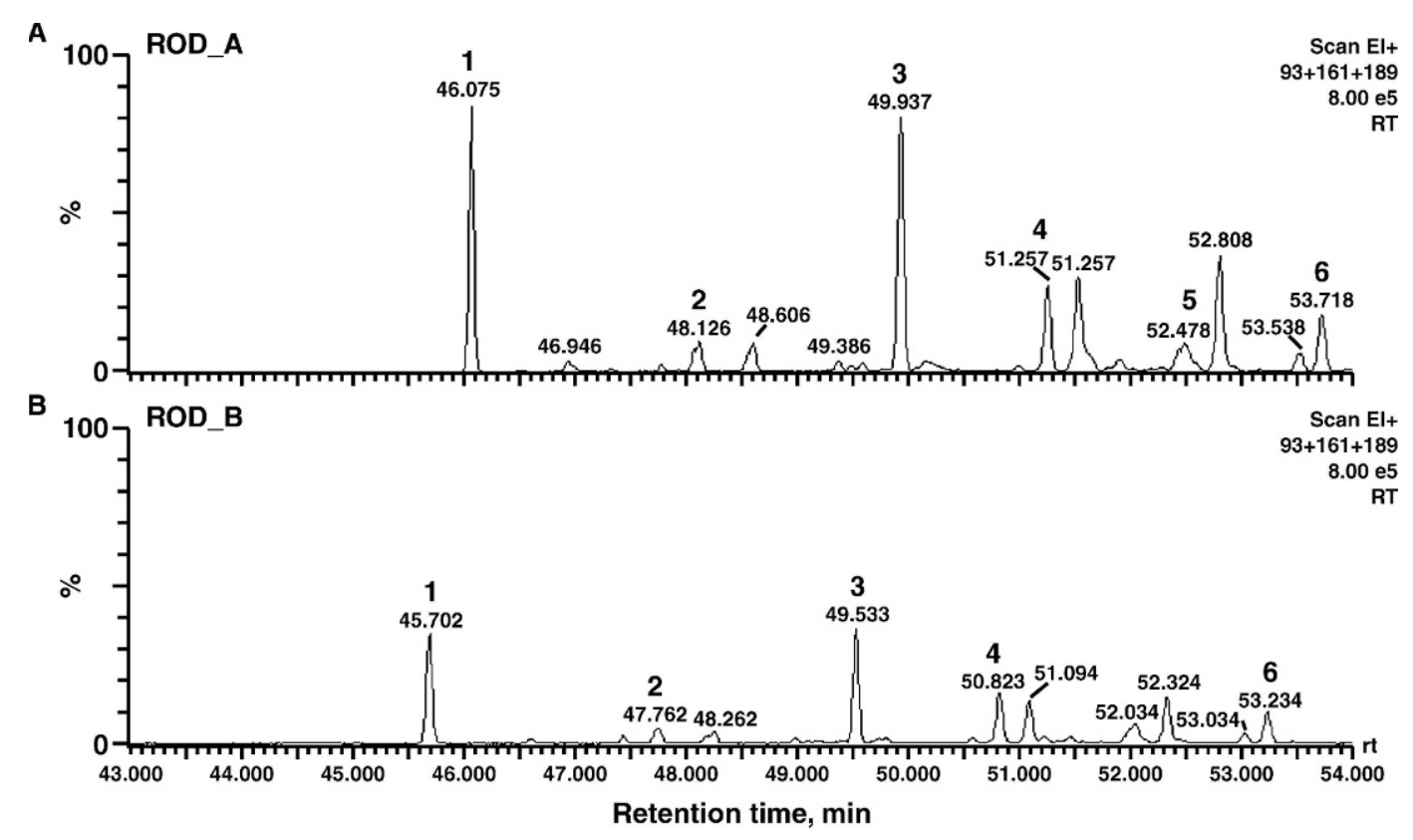

Figure 1. Comparison of chromatographic profiles of a cheese sample obtained with carboxen/polydimethylsiloxane (PDMS) (A) and PDMS fiber (B). Identified peaks: $1=$ triisopropylbenzene; $2=$ ethyldecanoate; $3=\beta$-caryophyllene; $4=$ dodecenolacetate; $5=$ valencene; $6=\delta$-cadinene.

origin of cheese, and consequently justify the higher price of mountain cheese. In particular, the following types of samples were analyzed: 1) cheese produced in summer, 2) the milk used to make it, and 3) the herbaceous species found in the mountain pastures on which animals grazed.

\section{MATERIALS AND METHODS}

\section{Reagents}

$\alpha$-Pinene, $\beta$-pinene, citronellene, camphene, $\beta$-mircene, $\alpha$-phellandrene, 3 -carene, $\alpha$-terpinene, $\gamma$-terpinene, m-cymene, p-cymene, limonene, terpineol, linalool, 5,7-dimethyl-1,6-octadiene, $\beta$-caryophyllene, $\alpha$ humulene, $\alpha$-cedrene, $\beta$-cedrene, $\alpha$-copaene, $\alpha$-cubebene, and triisopropyl benzene (TIPB; 97\%) were purchased from Aldrich/Fluka (Milan, Italy) and used as purchased. Standard solutions of terpenes and sesquiterpenes were prepared in ethanol (99.8\%; Fluka) and then diluted as needed.

\section{Apparatus and Operating Conditions}

A Fison (Beverly, MA) GC 8000-MD 800 instrument for GC-MS was used. The operating conditions were: injection port temperature, $280^{\circ} \mathrm{C}$; carrier gas, He at 1 $\mathrm{mL} / \mathrm{min}$; SPB-5 and EQUITY-5 Supelco (Bellefonte, PA) columns, both $60 \mathrm{~m} \times 0.32 \mathrm{~mm}$ i.d., film thickness 1.0 $\mu \mathrm{m}$; splitless mode with fiber; splitless time, $1 \mathrm{~min}$; temperature program, $5 \mathrm{~min}$ at $80^{\circ} \mathrm{C}$, increased to $110^{\circ} \mathrm{C}$ at $5^{\circ} \mathrm{C} / \mathrm{min}$, increased to $140^{\circ} \mathrm{C}$ at $1^{\circ} \mathrm{C} / \mathrm{min}$, then to $200^{\circ} \mathrm{C}$ at $10^{\circ} \mathrm{C} / \mathrm{min}$, and held for $10 \mathrm{~min}$; GC-MS interface temperature, $250^{\circ} \mathrm{C}$. Mass spectrometry operating conditions: ion source, $\mathrm{EI}+(70 \mathrm{eV})$; source temperature, $200^{\circ} \mathrm{C}$.

The SPME fibers used were polydimethylsiloxane (PDMS) $100 \mu \mathrm{m}$, polyacrylate $85 \mu \mathrm{m}$, PDMS/divinylbenzene $65 \mu \mathrm{m}$, and carboxen/PDMS $85 \mu \mathrm{m}$ (StableFlex Supelco). The vials were held at a constant temperature of $40^{\circ} \mathrm{C}$ with the SPME sampling stand (Supelco).

\section{Procedures}

Sample preparation. Samples of herbage, milk, and cheese were stored at $-18^{\circ} \mathrm{C}$. Herbage was thawed before analysis. For analysis of cheese, $10 \mathrm{~g}$ of grated Asiago cheese was put into a 50-mL round-bottomed flask, heated to $50^{\circ} \mathrm{C}$, connected to a vacuum pump by means of a U-shaped glass tube and a trap, and cooled at $-196^{\circ} \mathrm{C}$ in liquid nitrogen. The cheese sample was distilled for $2 \mathrm{~h}$ and headspace sampling was carried out on the recovered aqueous solution. For milk analysis, $200 \mathrm{~mL}$ was coagulated with $5 \mathrm{~mL}$ of glacial acetic acid and filtered through filter paper. Ten grams of the curd was vacuum distilled as described earlier.

Choice of fiber and sampling conditions. The performances of various kinds of fiber (PDMS, polyacry- 

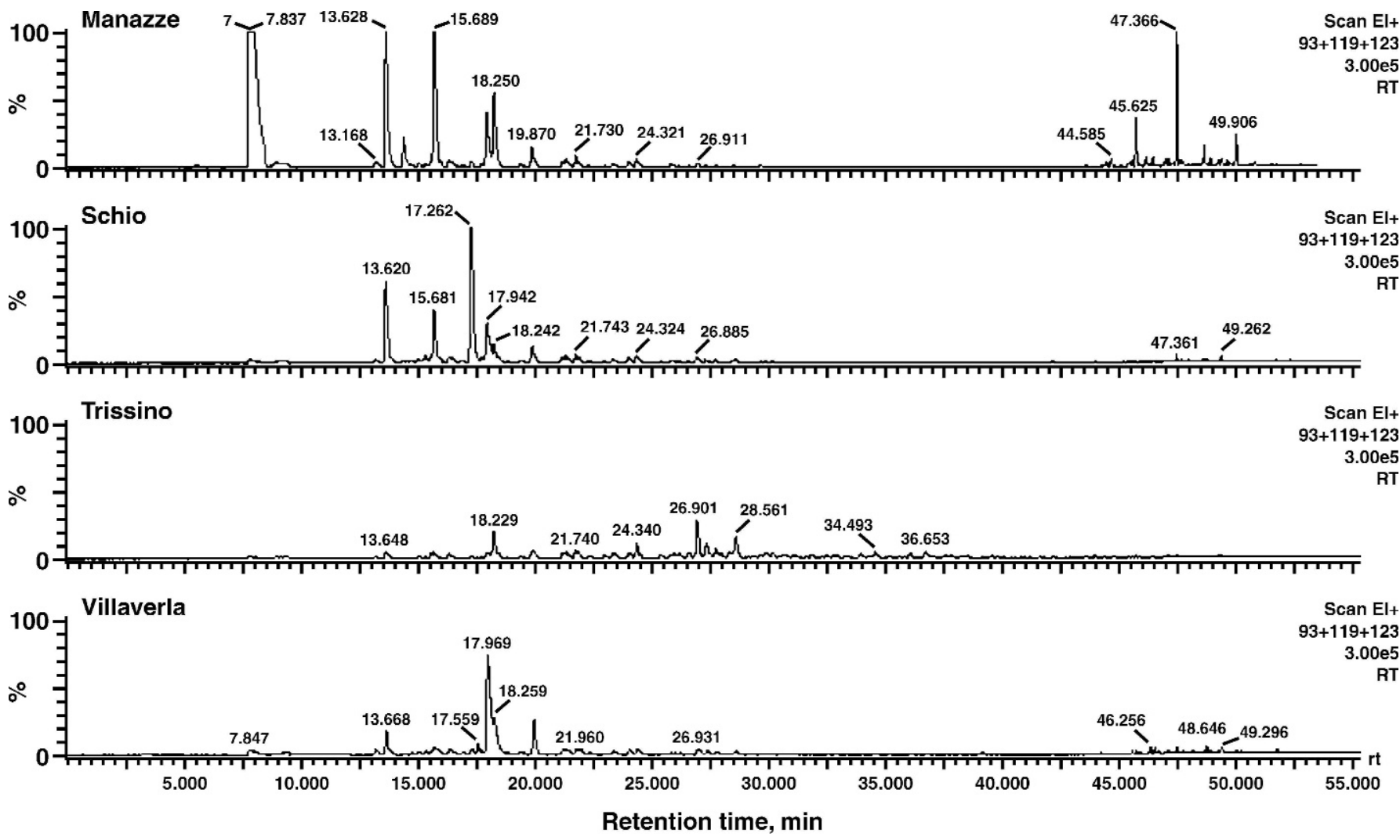

Figure 2. Chromatograms of 1 Asiago mountain cheese sample (Manazze) and 3 samples of Asiago lowland cheese of different provenance, obtained by solid-phase microextraction-gas chromatography-mass spectrometry using mass/charge values characteristic of the fragmentation of terpenes and sesquiterpenes $(93,119,123)$.

late, PDMS/divinylbenzene, and carboxen/PDMS) were evaluated to find the most suitable for sampling terpenes. The best results, in terms of terpene peak heights on cheese samples (Figure 1), were obtained with the carboxen/PDMS coating, in agreement with some reports (Pérès et al., 2001; Lee et al., 2003). However, for quantitative analysis, the PDMS fiber was preferred, which will be discussed later.

The volatile fraction was sampled by exposing the fiber in the headspace of a 40-mL vial containing either $2 \mathrm{~g}$ of herbage, thawed and ground, or the distilled aqueous solution from the milk and cheese samples. Tests with exposure times between 10 and $40 \mathrm{~min}$ and temperatures between 20 and $60^{\circ} \mathrm{C}$ revealed no appreciable differences, indicating that equilibrium between fiber and headspace was achieved in these conditions (Ai, 1997). In any case, out-of-equilibrium reproducible measurements can still be obtained if time, temperature, and solution volume are rigorously constant (Ai, 1997; Górecki and Pawliszyn, 1997). The conditions of $20 \mathrm{~min}$ and $40^{\circ} \mathrm{C}$ were chosen to ensure high robustness of the analytical procedure.
Blanks performed with fiber after GC-MS sample analysis indicated the absence of any carryover effect, due to efficient desorption at the chosen high temperature, $280^{\circ} \mathrm{C}$.

Table 1. Compounds corresponding to peaks shown in Figure 2.

\begin{tabular}{|c|c|}
\hline Compound & $\begin{array}{l}\text { Retention } \\
\text { time, min }\end{array}$ \\
\hline$\alpha$-Pinene ${ }^{1}$ & 13.63 \\
\hline$\delta$-Carene & 13.67 \\
\hline$\beta$-Pinene ${ }^{1}$ & 15.70 \\
\hline$\gamma$-Terpinene ${ }^{1}$ & 17.56 \\
\hline Diethylbenzene & 17.94 \\
\hline Limonene $^{1}$ & 18.25 \\
\hline Ethyldimethylbenzene & 19.87 \\
\hline Propylhexanoate & 21.73 \\
\hline Butylhexanoate & 24.32 \\
\hline Dimethylpropylbenzene & 28.56 \\
\hline$\alpha$-Longipinene & 44.58 \\
\hline$\alpha$-Cubebene ${ }^{1}$ & 45.62 \\
\hline Benzoimidazol-2-1 & 46.26 \\
\hline$\beta$-Caryophyllene ${ }^{1}$ & 47.37 \\
\hline Silane & 49.26 \\
\hline
\end{tabular}

${ }^{1}$ Standard available. 


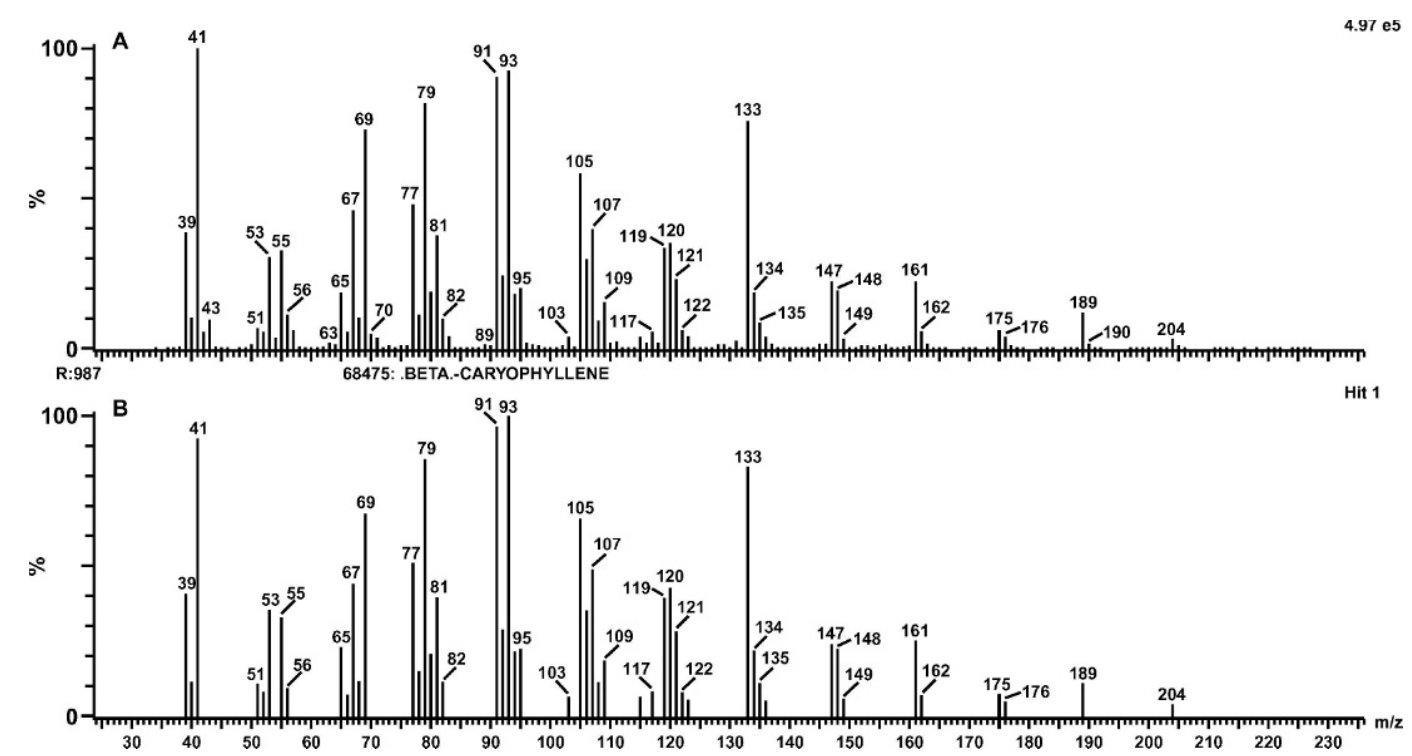

Figure 3. Mass fragmentation pattern of $\beta$-caryophyllene in a cheese sample (upper panel) and of library reference (lower panel).

Fiber calibration. To standardize the fiber, aqueous calibration solutions were prepared in a $40-\mathrm{mL}$ vial. To $3 \mathrm{~mL}$ of MilliQ water (MilliQ-Plus system, Millipore, Bedford, MA) was added 25 to $100 \mu \mathrm{L}$ of a $15 \mu \mathrm{g} / \mathrm{mL}$ caryophyllene solution in ethanol and $25 \mu \mathrm{L}$ of an 11 $\mu \mathrm{g} / \mathrm{L}$ TIPB solution in ethanol (internal standard). The calibrating solution volume in the vial was the same as that obtained by distillation of $10 \mathrm{~g}$ of cheese, used for analysis, following Górecki and Pawliszyn (1997).

Standard additions. Sesquiterpenes in cheese were quantified using the standard addition method. Four cheese samples, 1 uncontaminated and 3 fortified with increasing amounts of caryophyllene, were distilled following the reported procedure. The recovered solutions were analyzed by the SPME-GC-MS method. All cheese samples were spiked with the internal standard, TIPB.

Identification of terpenes and sesquiterpenes. Chromatograms were recorded with total ion current monitoring and then selecting characteristic terpene fragments (m/e: 93, 119, 123) to increase selectivity. Terpenes and sesquiterpenes were identified, when possible, by comparing their mass spectra with those obtained from available standards (indicated in tables). For the others, identification by mass library (National Institute of Standards and Technology) was carried out, accepting an identification level higher than $90 \%$.

Detection limit. The usual approach using the calibration line was followed (Vial and Jardy, 1999):

$$
\mathrm{L}_{\mathrm{D}}=\mathrm{b}_{0}+3 \mathrm{~S}_{\mathrm{b}_{0}}=\mathrm{b}_{0}+\mathrm{b}_{1} \mathrm{x}_{\mathrm{D}} \text { and } \mathrm{X}_{\mathrm{D}}=\frac{3 \mathrm{~S}_{\mathrm{b}_{0}}}{\mathrm{~b}_{1}}
$$

\section{RESULTS AND DISCUSSION}

\section{Preliminary Analysis of Asiago Cheese Samples of Certain Origin}

As a first screening step, Asiago cheese samples of different origins were analyzed. Samples came from the Asiago plateau (about $1500 \mathrm{~m}$ above sea level) and from lowland areas. The mountain cheese had been produced with milk from animals feeding on mountain pastures, and lowland cheese from animals feeding on lowland grass, hay, or fodder. All cheese samples were produced with partially skimmed milk and then ripened for 3 mo. The following samples were analyzed: 6 certain mountain cheeses, 3 presumed mountain cheeses, 3 lowland cheeses, and 2 cheeses from animals fed on a variable diet.

No result was obtained with direct sampling of volatiles on Asiago cheese, probably owing to the high affinity of terpenes for the lipidic matrix and consequently, their excessively low concentration in the headspace. On the other hand, good results were obtained by enrichment of terpenes by distillation under vacuum of cheese.

\section{Identification of Markers}

Preliminary results indicated the presence of terpenes and sesquiterpenes in cheese produced with milk from animals feeding on mountain pastures. A typical example is given by the chromatograms of Figure 2, obtained with mass/charge values characteristic of the fragmentation of terpenes and sesquiterpenes to in- 
Table 2. Characteristics of mountain pastures.

\begin{tabular}{lclcc}
\hline Name of farm & Biancoia & Laste Manazzo & Mandrielle N.P. & Mandrielle V.P. \\
\hline Location & Conco & Luisiana & Rotzo & Rotzo \\
Exposure, ${ }^{\circ}$ from north & $0-270$ & $25-290$ & $145-270$ & $200-255$ \\
Altitude, m above sea level & 1095 & 1655 & 1585 & 1560 \\
No. of animals & 130 & 95 & 45 & 30 \\
Soil depth, cm & 14 & $16-18$ & $20-24$ & - \\
pH & 6 & 4.7 & 5.8 & - \\
Organic matter, \% & 14 & 22 & 23 & - \\
Gradient, \% & $0-40$ & $15-50$ & $10-15$ & $3-7$ \\
Area with vegetation, \% & 96 & $98-100-100$ & $98-99$ & $98-99$ \\
Area with herbaceous species, \% & 100 & 99.8 & 100 & 99 \\
Area with shrubs, \% & 0 & 0.2 & 0 & 1 \\
No. herbaceous species & $21-45$ & $31-45$ & $43-50$ & $36-46$ \\
\hline
\end{tabular}

crease detection selectivity. They show a greater amount of terpenes in mountain cheeses than in lowland ones, and the presence of sesquiterpenes (retention time higher than $40 \mathrm{~min}$ ) exclusively in mountain products. Table 1 lists the retention times of the peaks shown in Figure 2, the species identified, and the m/e values used. Figure 3 shows, for example, the fragmentation pattern of caryophyllene in a cheese sample, and that of the National Institute of Standards and technology library. These findings indicate that sesquiterpenes can effectively be used as markers of cheeses of mountain origin, because they discriminate between products made with milk from animals feeding on mountain pastures and animals fed on lowland hay or fodder.

\section{Analysis of Mountain Herbage, Milk, and Cheese}

In a subsequent step of the work, an effective correlation between the presence of sesquiterpenes in mountain herbage, milk, and cheese was sought, and samples were taken from 4 farms on the Asiago plateau. In Table 2 , some typical farm characteristics are reported: the locality, altitude, dimension, the floristic composition of the pastures; all data were in agreement with the required genuineness of the examined products.

Sampling of herbage was made in summer, together with the milk produced by the animals on these farms, and the resulting cheeses were marked and stored for a short ripening time (3 mo).

Table 3 lists the herbaceous species collected from the 4 pastures, and shows the results of GC-MS analysis. Many of the mountain species contained sesquiterpenes, some in appreciable amounts, whereas lowland species contained only small amounts of sesquiterpenes, with the exception being Achillea millefolium $\mathrm{L}$.

The detected sesquiterpenes are listed in Table 4, and an example of a relative chromatogram is given in Figure 4. For comparison, Figure 5 shows the chromatograms of 4 mountain milk samples and 1 lowland sample. Apart from the peak at $46.5 \mathrm{~min}$, identified as dec- anoic acid, no peak appeared in the chromatogram of lowland milk, whereas at least 3 sesquiterpenes with signal-to-noise ratios higher than the critical level, $\mathrm{L}_{\mathrm{C}, \alpha=0.05}$, defined as $1.65 \cdot \mathrm{S}_{\mathrm{NOISE}}$ (Vial and Jardy, 1999), were detected in mountain milk samples. Fewer sesquiterpenes were found in mountain milk than in mountain herbage, as shown in Table 5.

Lastly, in every cheese sample from the 4 farms, $\beta$ caryophyllene and $\alpha$-humulene prevailed, together with other sesquiterpenes like isocaryophyllene or others not identified, at trace level. It may be noted that $\beta$-caryophyllene, frequently the most abundant in herbage, and its isomer $\alpha$-humulene, are the prevailing species in cheese.

\section{Quantitative Analysis}

The possibility of quantitative analysis was verified by measuring the carboxen/PDMS fiber response for

Table 3. Herbage collected from 4 farms on Asiago plateau (typical mountain species are shown in bold type).

\begin{tabular}{lll}
\hline Farm & Species & Sesquiterpenes \\
\hline Biancoia & Cynosurus cristatus $\mathrm{L}$. & + \\
& Dactylis glomerata $\mathrm{L}$. & Trace \\
& Festuca rubra $\mathrm{L}$. & - \\
& Leontodon hispidus & ++ \\
& Phleum pratense $\mathrm{L}$. & Trace \\
& Taraxacum officinale $\mathrm{W}$. & + \\
Laste Manazzo & Achillea millefolium $\mathrm{L}$. & ++ \\
& Agrostis tenuis $\mathrm{S}$. & Trace \\
& Alchemilla xanthochlora R. & +++ \\
& Festuca rubra $\mathrm{L}$. & - \\
& Koeleria pyramidata $\mathrm{D}$. & + \\
& Phleum alpinum $\mathrm{L}$. & Trace \\
& Poa alpina $\mathrm{L}$. & Trace \\
Mandrielle N.P. & Dactylis glomerata $\mathrm{L}$. & - \\
& Koeleria pyramidata $\mathrm{D}$. & + \\
Mandrielle V.P. & Cynosurus cristatus $\mathrm{L}$. & + \\
& Dactylis glomerata $\mathrm{L}$. & Trace \\
& Lotus corniculatus $\mathrm{L}$. & + \\
& Thymus pulegioides $\mathrm{L}$. & +++ \\
\hline
\end{tabular}


Table 4. Sesquiterpenes detected in mountain herbage, with most abundant types shown in bold type. Retention times are different from those in Table 1 because they were obtained using a different column.

\begin{tabular}{|c|c|}
\hline Sesquiterpene & $\begin{array}{l}\text { Retention } \\
\text { time, min }\end{array}$ \\
\hline Acetoxy-p-menthene & 49.48 \\
\hline Alloaromandrene & 51.09 \\
\hline Bergamotene & 51.96 \\
\hline$\beta$-Bisabolene & 52.31 \\
\hline$\beta$-Bourbonene & 48.15 \\
\hline$\beta$-Caryophyllene ${ }^{1}$ & 49.51 \\
\hline Caryophyllene oxide & 52.08 \\
\hline$\alpha$-Copaene $^{1}$ & 47.86 \\
\hline$\beta$-Cubebene & 49.45 \\
\hline$\alpha$-Cubebene $^{1}$ & 47.90 \\
\hline Hedycaryol & 54.32 \\
\hline$\beta$-Elemene & 48.18 \\
\hline$\alpha$-Humulene ${ }^{1}$ & 50.79 \\
\hline Isocaryophyllene & 49.01 \\
\hline Longiciclene & 47.83 \\
\hline$\alpha$-Terpinyl acetate & 46.38 \\
\hline Trans- $\beta$-farnesene & 50.18 \\
\hline$\alpha$-Longipinene & 49.66 \\
\hline
\end{tabular}

${ }^{1}$ Standard available.

various concentrations of caryophyllene. Initially, the fiber was exposed to the headspace of aqueous solutions containing varying amounts of caryophyllene and a constant amount of the internal standard, TIPB. The ratio between caryophyllene areas and the TIPB area vs. caryophyllene concentration plotted along a straight line (Figure 6a) in the range 100 to $500 \mu \mathrm{g} / \mathrm{L}\left(\mathrm{b}_{0} \pm\right.$ $\mathrm{t}_{\alpha=0.05,2} \cdot \mathrm{S}_{\mathrm{b}_{0}}=0.17 \pm 0.04 ; \mathrm{b}_{1} \pm \mathrm{t}_{\alpha=0.05,2} \cdot \mathrm{S}_{\mathrm{b}_{1}}=0.0032 \pm$ $\left.0.0001 \mathrm{~L} / \mu \mathrm{g} ; \mathrm{R}^{2}=0.9998\right)$. This result verified fiber response linearity in the signal range, complying with the responses of the analyte found in cheese samples, and revealed a detection limit for the procedure of $\mathrm{x}_{\mathrm{D}}=3 \mathrm{~S}_{\mathrm{b}_{0}} / \mathrm{b}_{1}=9 \mu \mathrm{g} / \mathrm{L}$. However, as competition in the adsorbing process of numerous volatile compounds (Górecki et al., 1999; Black and Fine, 2001; Murray, 2001) may change the behavior of fiber when it is exposed to solutions distilled from cheese samples, with a consequent matrix effect, the standard addition method was used. Various samples of the same cheese were spiked with increasing amounts of caryophyllene and a constant amount of TIPB, and then analyzed as described earlier. Unfortunately, results were not satisfactory, because neither linear behavior nor repeatable responses were obtained (Figure 6, b and c).

These unsatisfactory results fit the reports of several authors who state that simultaneous quantitative analysis of several volatile substances is very difficult when using fibers whose sampling mechanism is competitive adsorption of the species (Górecki et al., 1999; Black and Fine, 2001; Murray, 2001). Consequently, quantitative analysis was again carried out using PDMS coating in place of carboxen/PDMS. Both external calibration with standard aqueous solutions of caryophyllene/TIPB and the standard addition procedure were carried out. External calibration gave a response similar to that of carboxen/PDMS coating, and standard additions to the 4 cheese samples in this case gave a linear plot. Repeated measures on the solutions distilled from the fortified samples indicated the obtainable repeatability. Figure 7 shows a straight line with a $95 \%$ confidence interval for the Pozza cheese sample. Table 6 lists the caryophyllene amounts found in the various Asiago cheese samples with internal calibration.

\section{Precision Estimates}

Precision was evaluated by examining the various steps of the analytical procedure. First, analysis was repeated on the same solution, introducing the fiber

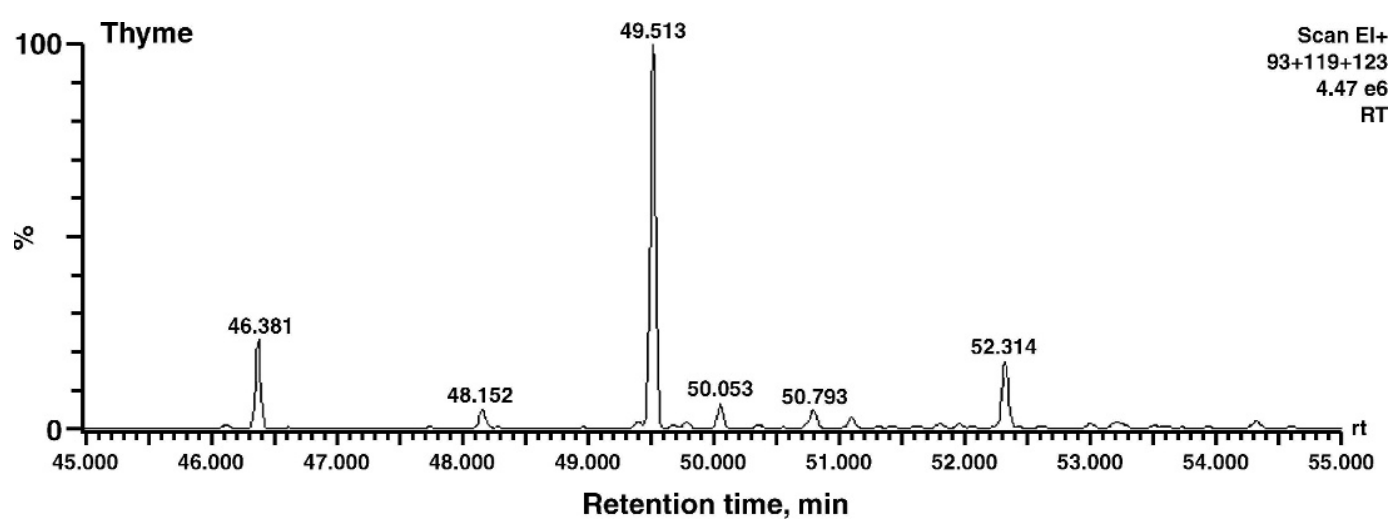

Figure 4. Chromatogram of a sample of thyme by solid-phase microextraction-gas chromatography-mass spectrometry using mass/charge values characteristic of fragmentation of terpenes and sesquiterpenes $(93,119,123)$. Peak at 46.38 min $=\alpha$-terpinyl acetate; at 48.15 min $=$ $\beta$-bourbonene; at $49.51 \mathrm{~min}=\beta$-caryophyllene; at $50.05 \mathrm{~min}=\operatorname{trans} \beta$-farnesene; at $50.79 \mathrm{~min}=\alpha$-humulene; and at $52.31 \mathrm{~min}=\beta$-bisabolene . Retention times are different from those in Figure 2 because of a change of column. 


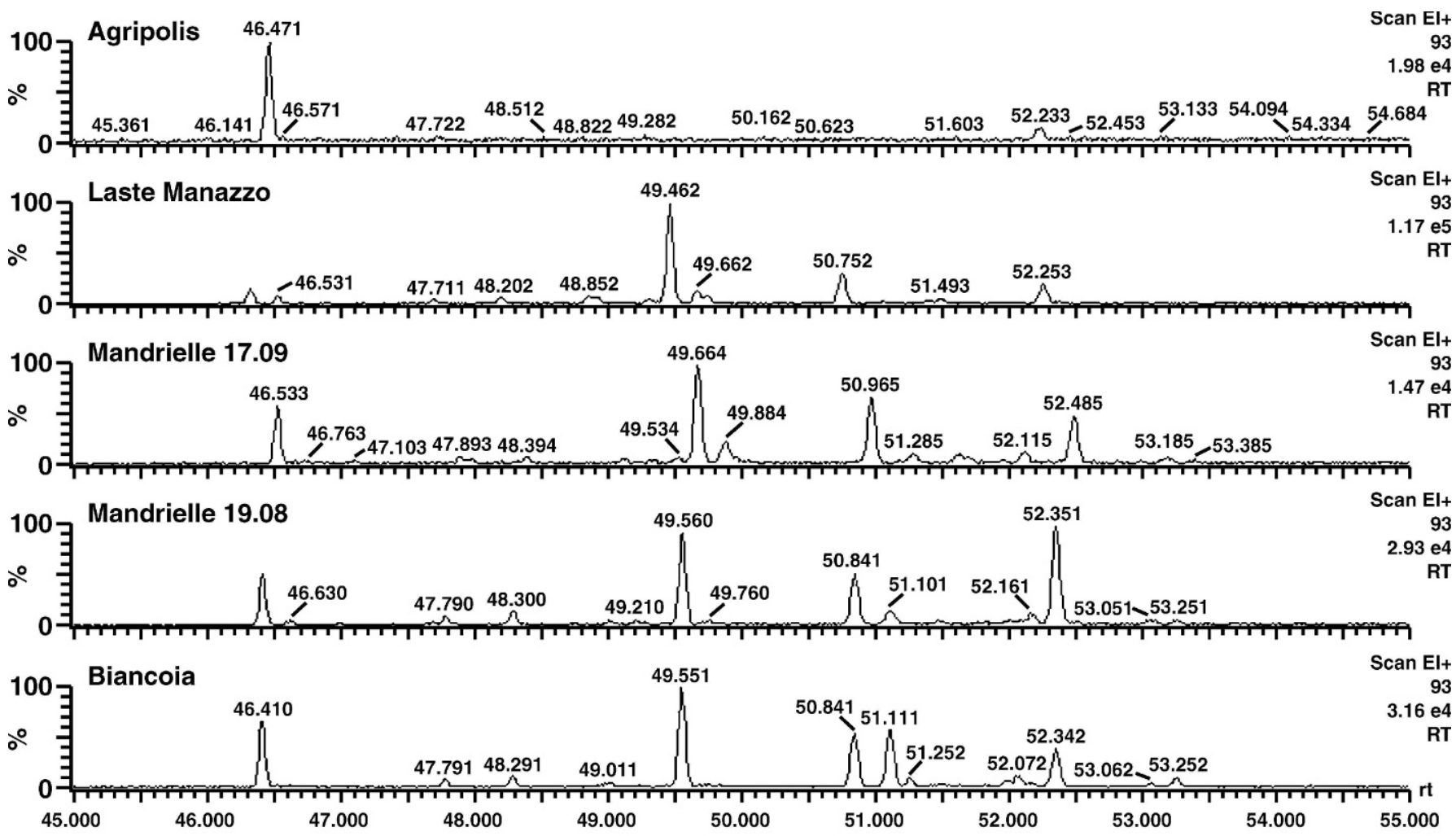

Retention time, $\min$

Figure 5. Chromatograms of 5 milk samples obtained with solid-phase microextraction-gas chromatography-mass spectrometry using only 1 mass/charge value (93). Top = lowland sample (Agripolis) followed by 4 mountain samples. Retention times are different from those in Figure 2 because a different column was used.

into the same vial. Only the first 2 tests were significant, because after the third test, the signal decreased progressively because of a non-negligible reduction in analyte concentration with successive fiber samplings. This test dealing with the repeatability of the analysis is a common practice for several authors (Almeida and Vilas

Table 5. Sesquiterpenes found in mountain milk.

\begin{tabular}{ll}
\hline Farm & Sesquiterpene \\
\hline Biancoia & $\beta$-Caryophyllene ${ }^{1}$ \\
& $\alpha$-Cubebene $^{1}$ \\
& $\alpha$-Humulene $^{1}$ \\
& Sesquiterpene $^{1}(51.1 \mathrm{~min})$ \\
& Sesquiterpene $^{-}(52.4 \mathrm{~min})$ \\
Laste Manazzo & $\beta$-Caryophyllene ${ }^{1}$ \\
Mandrielle N.P. & $\beta$-Caryophyllene ${ }^{1}$ \\
& $\beta$-Humulene \\
Mandrielle V.P. & $\gamma$-Muurolene \\
& $\beta$-Caryophyllene \\
& $\alpha$-Cubebene \\
& $\beta$-Humulene \\
& Sesquiterpene $(51.2 \mathrm{~min})$ \\
& Sesquiterpene $(52.3 \mathrm{~min})$ \\
&
\end{tabular}

\footnotetext{
${ }^{1}$ Standard available.
}

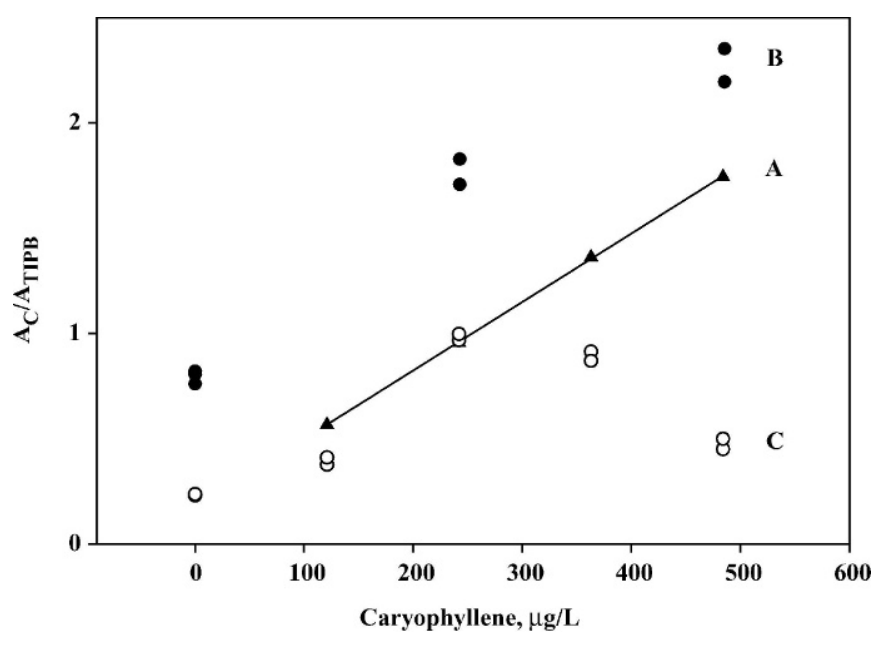

Figure 6. Calibration curves for caryophyllene obtained on carboxen/polydimethylsiloxane fiber (caryophyllene over triisopropyl benzene area ratio vs. caryophyllene concentration). Curve A shows external calibration; B and $\mathrm{C}$ are examples of standard additions on the same cheese. 


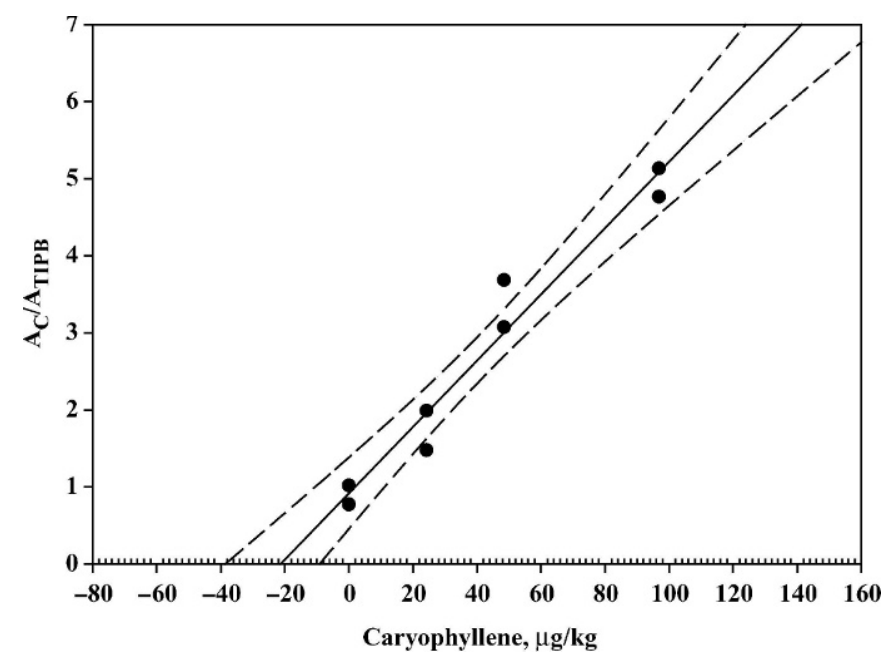

Figure 7. Calibration curve for caryophyllene obtained on polydimethylsiloxane fiber with standard additions method (caryophyllene over triisopropyl benzene area ratio vs. caryophyllene concentration in $\mu \mathrm{g} / \mathrm{kg}$ of cheese). Confidence bands show the $95 \%$ confidence level.

Boas, 2004). A more comprehensive relative standard deviation of the signal, evaluated by 2 repetitions on the solutions coming from 2 independent replicated cheese samples, was about $13 \%$ for a caryophyllene amount of about $70 \mu \mathrm{g} / \mathrm{kg}$ - a value higher than that found in the external calibration.

Finally, a more representative relative standard deviation of the signal, calculated at the same concentration value, was obtained by pooling the 4 regression variances of the internal calibrations for the 4 different cheese samples, after an $F$-test between the highest and the lowest one. It resulted to be about $10 \%$, in good agreement with the $13 \%$ reported above. This coincidence indicates that the cheese matrix is practically the same varying the considered farm. These results denote that competition and distillation play an important role in achievable precision.

\section{CONCLUSIONS}

The possibility of using sesquiterpenes as markers of Asiago mountain cheese was suggested by the chromatographic profiles of 13 authentic samples. In partic-

Table 6. Amounts of $\beta$-caryophyllene found in Asiago cheese samples.

\begin{tabular}{lll}
\hline Sample & $\begin{array}{l}\text { Quantity, } \\
\mu \mathrm{g} / \mathrm{kg}\end{array}$ & $\begin{array}{l}\text { Confidence } \\
\text { range, } \\
\mu \mathrm{g} / \mathrm{kg}\end{array}$ \\
\hline Martinello (Biancoia) & 62 & $34-114$ \\
Fontana (Laste Manazzo) & 21 & $9-39$ \\
Pozza (Mandrielle N.P.) & 65 & $34-125$ \\
Rodighiero (Mandrielle V.P.) & 36 & $22-55$ \\
\hline
\end{tabular}

ular, their traceability was demonstrated by analyzing herbaceous species, milk, and cheese produced with milk from animals grazing on mountain pastures of 4 different farms. Headspace SPME-GC-MS analysis was suitable for characterizing the profiles of terpenes and sesquiterpenes at trace level (10 to $100 \mu \mathrm{g} / \mathrm{kg}$ ).

The SPME technique, although not exhaustive, is much more economical than purge-and-trap sampling of volatile compounds, and allows identification and raw quantification of examined substances. Qualitative analysis may be performed with carboxen/PDMS fiber, but quantitative analysis is only possible with an absorbing type of fiber, PDMS, due to the concentrationdependent competition of various compounds, in the case of an adsorbing process. Many sesquiterpenes were found in mountain herbage, fewer in milk, and only 2 , $\beta$-caryophyllene and $\alpha$-humulene, in Asiago mountain cheese. The most abundant, $\beta$-caryophyllene, was found at levels of 21 to $65 \mu \mathrm{g} / \mathrm{kg}$. Precision was only moderate, as expected, due to the low level of the analytes quantified. The proposed method can quite satisfactorily perform qualitative and quantitative analysis of sesquiterpenes, and is suitable for identifying Asiago mountain cheese.

\section{ACKNOWLEDGMENTS}

This work was financially supported by the University of Padova, Italy. The authors are grateful to Flavio da Ronch, Department of Environmental Agronomy and Vegetal Productions, University of Padova, for collecting herbaceous species from mountain pastures and for floristic analysis, and to the "Consorzio per la tutela del formaggio Asiago" for providing Asiago cheese samples.

\section{REFERENCES}

Ai, J. 1997. Solid phase microextraction for quantitative analysis in nonequilibrium situations. Anal. Chem. 69:1230-1236.

Almeida, C. M. M., and L. Vilas Boas. 2004. Analysis of BTEX and other substituted benzenes in water using headspace SPME-GCFID: Method validation. J. Environ. Monit. 6:80-88.

Black, L., and D. Fine. 2001. High levels of monoaromatic compounds limit the use of solid-phase microextraction of methyl tert-butyl ether and tert-butyl alcohol. Environ. Sci. Technol. 35:3190-3192.

Bugaud, C., S. Buchin, J.-B. Coulon, A. Hauwuy, and D. Dupont. 2001a. Influence of the nature of alpine pastures on plasmin activity, fatty acid and volatile compound composition of milk. Lait 81:401-414.

Bugaud, C., S. Buchin, A. Hauwuy, and J.-B. Coulon. 2001c. Relationship between flavour and chemical composition of Abondance cheese derived from different types of pastures. Lait 81:757-773.

Bugaud, C., S. Buchin, Y. Noël, L. Tessier, S. Pochet, B. Martin, and J. F. Chamba. 2001b. Relationship between Abondance cheese texture, its composition and that of milk produced by cows grazing different types of pastures. Lait 81:593-607.

Cardinal, M., C. Viallon, C. Thonat, and J. L. Berdague. 2001. Pyrolysis-mass spectrometry for rapid classification of oysters according to rearing area. Analusis 28:825-829. 
Careri, M., L. Elviri, A. Mangia, I. Zagnoni, C. Agrimonti, G. Visioli, and N. Marmiroli. 2003. Analysis of protein profiles of genetically modified potato tubers by matrix-assisted laser desorption/ionization time-of-flight mass spectrometry. Rapid Commun. Mass Spectrom. 17:479-483.

Contarini, G., and M. Povolo. 2002. Volatile fraction of milk: Comparison between purge and trap and solid phase microextraction techniques. J. Agric. Food Chem. 50:7350-7355.

Cozzolino, D., V. Martins, and I. Murray. 2002. Visible and near infrared spectroscopy of beef longissimus dorsi muscle as a means of discriminating between pasture and corn silage feeding regimes. J. Near-Infrared Spectrosc. 10:187-193.

Fernandez, C., C. Astier, E. Rock, J. B. Coulon, and J. L. Berdague. 2003. Characterization of milk by analysis of its terpene fractions. Int. J. Food Sci. Technol. 38:445-451.

Górecki, T., and J. Pawliszyn. 1997. Effect of sample volume on quantitative analysis by solid-phase microextraction. Part 1. Theoretical considerations. Analyst 112:1079-1086.

Górecki, T., X. Yu, and J. Pawliszyn. 1999. Theory of analyte extraction by selected porous polymer SPME fiber. Analyst 124:643649.

Jaillais, B., V. Bertrand, and J. Auger. 1999. Cryo-trapping/SPME/ GC analysis of cheese aroma. Talanta 48:747-753.

Lecanu, L., V. Ducruet, C. Jouquand, J. J. Gratadoux, and A. Feigenbaum. 2002. Optimization of headspace solid-phase microextraction (SPME) for the odor analysis of surface-ripened cheese. J. Agric. Food Chem. 50:3810-3817.

Lee, J.-H., R. Diono, G.-Y. Kim, and D. B. Min. 2003. Optimization of solid phase microextraction analysis for the headspace volatile compounds of Parmesan cheese. J. Agric. Food Chem. 51:11361140 .

Mariaca, R. G., T. F. H. Berger, R. Gauch, M. I. Imhof, B. Jeangros, and J. O. Bosset. 1997. Occurrence of volatile mono- and sesquiterpenoids in highland and lowland plant species as possible precursors for flavor compounds in milk and dairy products. J. Agric. Food Chem. 45:4423-4434.

Mauriello, G., L. Moio, A. Genovese, and D. Ercolini. 2003. Relationships between flavoring capabilities, bacterial composition, and geographical origin of natural whey cultures used for traditional water-buffalo Mozzarella cheese manufacture. J. Dairy Sci. 86:486-497.

Murray, R. A. 2001. Limitations to the use of solid phase microextraction for quantitation of mixtures of volatile organic sulfur compounds. Anal. Chem. 73:1646-1649.
Pérès, C., C. Viallon, and J.-L. Berdagué. 2001. Solid-phase microextraction-mass spectrometry: A new approach to the rapid characterisation of cheeses. Anal. Chem. 73:1030-1036.

Pillonel, L., B. Albrecht, R. Badertscher, U. Butikofer, J. F. Chamba, R. Tabacchi, and J. O. Bosset. 2003b. Analytical methods for the determination of the geographic origin of Emmental cheese: Parameters of proteolysis and rheology. Ital. J. Food Sci. 15:49-62.

Pillonel, L., S. Ampuero, R. Tabacchi, and J. O. Bosset. 2003a. Analytical methods for the determination of the geographic origin of Emmental cheese: Volatile compounds by GC/MS-FID and electronic nose. Eur. Food Res. Technol. 216:179-183.

Pillonel, L., J. O. Bosset, and R. Tabacchi. 2002. Rapid preconcentration and enrichment techniques for the analysis of food volatile. A review. Lebensm. Wiss. Technol. 35:1-14.

Pillonel, L., W. Luginbuhl, D. Picque, E. Schaller, R. Tabacchi, and J. O. Bosset. 2003c. Analytical methods for the determination of the geographic origin of Emmental cheese: Mid- and near-infrared spectroscopy. Eur. Food Res. Technol. 216:174-178.

Pinho, O., I. M. P. L. V. O. Ferreira, and M. Ferreira. 2004. Discriminate analysis of volatile fraction from "Terrincho" ewe cheese: Correlation with flavour characteristics. Int. Dairy J. 14:455-464.

Pinho, O., I. M. P. L. V. O. Ferreira, and M. A. Ferreira. 2002. Solid phase microextraction in combination with GC/MS for quantification of the major volatile free fatty acids in ewe cheese. Anal. Chem. 74:5199-5204.

Pinho, O., C. Pérès, and I. M. P. L. V. O. Ferreira. 2003. Solid phase microextraction of compounds in "Terrincho" ewe cheese. Comparison of different fibers. J. Chromatogr. A. 1011:1-9.

Plastow, G. S., A. Mileham, T. Wilken, C. Gladney, and J. Bastiaansen. 2003. Patent PCT Int. Appl. WO 2003087765 A2 23 Oct 2003, 34 pp. Pig Improvement Co. UK Ltd., UK.

Povolo, M., and G. Contarini. 2003. Comparison of solid-phase microextraction and purge-and-trap methods for the analysis of the volatile fraction of butter. J. Chromatogr. A. 985:117-125.

Vial, J., and A. Jardy. 1999. Experimental comparison of the different approaches to estimate LOD and LOQ of an HPLC method. Anal. Chem. 71:2672-2677.

Viallon, C., B. Martin, I. Verdier-Metz, P. Pradel, J.-P. Garel, J.-B. Coulon, and J.-L. Berdagué. 2000. Transfer of monoterpenes and sesquiterpenes from forages into milk fat. Lait 80:635-641.

Viallon, C., I. Verdier-Metz, C. Denoyer, P. Pradel, J.-B. Coulon, and J.-L. Berdagué. 1999. Desorbed terpenes and sesquiterpenes from forages and cheeses. J. Dairy Sci. 66:319-326. 